\title{
Continuous multistep synthesis of 2-(azidomethyl)oxazoles
}

\author{
Thaís A. Rossa ${ }^{1,2}$, Nícolas S. Suveges ${ }^{3}$, Marcus M. Sá2 ${ }^{2}$ David Cantillo ${ }^{* 1,4}$ \\ and C. Oliver Kappe ${ }^{* 1,4}$
}

\author{
Full Research Paper \\ Address: \\ ${ }^{1}$ Institute of Chemistry, University of Graz, NAWI Graz, \\ Heinrichstrasse 28, 8010 Graz, Austria, ${ }^{2}$ Departamento de Química, \\ Universidade Federal de Santa Catarina, Florianópolis 88040-900, \\ SC, Brazil, ${ }^{3}$ Chemistry Institute, Federal University of Rio de Janeiro, \\ Rio de Janeiro, RJ, Brazil 22941-909, and ${ }^{4}$ Research Center \\ Pharmaceutical Engineering GmbH (RCPE), Inffeldgasse 13, 8010 \\ Graz, Austria \\ Email: \\ David Cantillo* - david.cantillo@rcpe.at; C. Oliver Kappe* - \\ oliver.kappe@uni-graz.at \\ * Corresponding author \\ Beilstein J. Org. Chem. 2018, 14, 506-514. \\ doi:10.3762/bjoc. 14.36 \\ Received: 22 November 2017 \\ Accepted: 08 February 2018 \\ Published: 23 February 2018 \\ This article is part of the Thematic Series "Integrated multistep flow \\ synthesis". \\ Guest Editor: V. Hessel \\ (C) 2018 Rossa et al.; licensee Beilstein-Institut. \\ License and terms: see end of document. \\ Keywords: \\ azirines; continuous flow; heterocycles; oxazoles; process integration; \\ vinyl azides
}

\begin{abstract}
An efficient three-step protocol was developed to produce 2-(azidomethyl)oxazoles from vinyl azides in a continuous-flow process. The general synthetic strategy involves a thermolysis of vinyl azides to generate azirines, which react with bromoacetyl bromide to provide 2-(bromomethyl)oxazoles. The latter compounds are versatile building blocks for nucleophilic displacement reactions as demonstrated by their subsequent treatment with $\mathrm{NaN}_{3}$ in aqueous medium to give azido oxazoles in good selectivity. Process integration enabled the synthesis of this useful moiety in short overall residence times ( 7 to $9 \mathrm{~min}$ ) and in good overall yields.
\end{abstract}

\section{Introduction}

Oxazoles are an important class of five-membered aromatic heterocycles containing one oxygen and one nitrogen atom in their structures. The oxazole moiety is relatively stable and is found widely in nature [1-3]. Naturally occurring oxazoles include compounds with antibiotic or antimicrobial properties such as pimprinine [4] or phenoxan [5] (Figure 1a). Also many synthetic active pharmaceutical ingredients (API) contain the oxazole as an active moiety [1-3]. Oxaprozin, for example, is an important non-narcotic, non-steroidal anti-inflammatory drug $[6,7]$. Sulfamoxole is a broad-spectrum antibiotic for the treatment of bacterial infections (Figure 1b) [8]. In addition, ongoing studies show the potential of amino and amidooxazoles to act as fluorescent dipeptidomimetics (Figure 1c) [9]. Due to their diene character, oxazoles find also use as intermediates in the synthesis of other organic scaffolds such as furans and pyridines, via cycloaddition/retro-cycloaddition 
(a)<smiles>Cc1ncc(C2=CNC3C=CC=CC23)o1</smiles>

pimprinine<smiles>CCc1c(-c2coc(CC/C(C)=C/c3ccccc3)n2)oc(OC)c(C)c1=O</smiles><smiles>O=C(O)CCc1nc(-c2ccccc2)c(-c2ccccc2)o1</smiles>

oxaprozin (c)<smiles>Cc1nc(NS(=O)(=O)c2ccc(N)cc2)oc1C</smiles><smiles>[R]NCc1nc(C(=O)O[R1])c([Te])o1</smiles>

sulfamoxole (d)

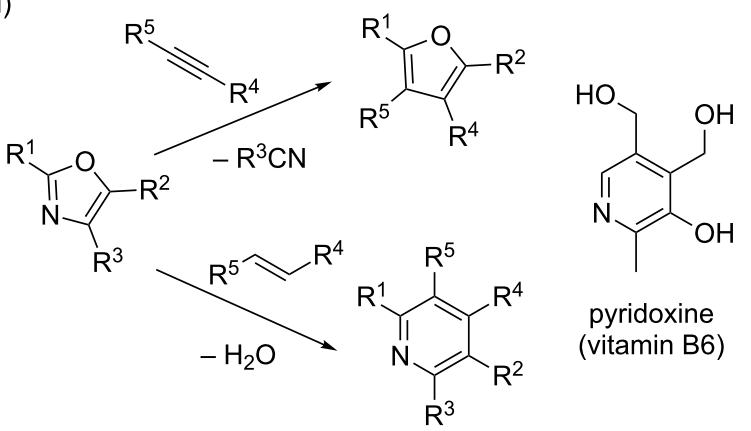

Figure 1: Examples of naturally occurring oxazoles (a); some drugs containing oxazole as the active moiety (b); general structure of fluorescent dipeptidomimetics derived from trisubstituted oxazoles (c); reactivity of the oxazole system as an azadiene (d).

tandem processes (Figure 1d) [10-13]. A classical example is the preparation of pyridoxine (a form of vitamin B6) using this approach $[14,15]$.

There are several methods for the preparation of oxazoles described in the literature. These include ring-closure reactions of diazocarbonyl compounds with amides or nitriles [16], $\alpha$-haloketones and amides [17-19], cyanohydrins and aldehydes (Fischer synthesis) [20,21], or oxidative additions of $\alpha$-methylene ketones to nitriles $[22,23]$. An alternative approach consists of the ring expansion of azirines, which can be prepared from vinyl azides 1 , by the reaction with carbonyl compounds. Substituted 2-acylazirines rearrange to oxazoles in the presence of bases [24-26]. In addition the light-mediated synthesis of oxazoles from azirines and aldehydes also has been described by Lu and Xiao [27]. Hassner and Fowler described the reaction of azirines 2 with acyl chlorides with formation of intermediate adduct $\mathbf{3}$ to give oxazoles $\mathbf{4}$ in polar solvents (Scheme 1)
$[28,29]$. In the latter reaction amide $\mathbf{5}$ was formed as a sideproduct and the aziridine intermediate $\mathbf{3}$ was stable and could be isolated when the reaction was carried out in non-polar solvents.<smiles>[R]C1N=C1Pc1ccccc1</smiles><smiles>[R]c1nc(-c2ccccc2)oc1-c1ccccc1</smiles>

Scheme 1: Synthesis of oxazoles 4 by addition of acyl chlorides to azirines 2, as described by Hassner et al. [28,29].

In particular, 2-(halomethyl)oxazoles 6 are a class of compounds rather underexplored, even though they are frequently key intermediates in the total synthesis of natural products [30-32]. Recently, Patil and Luzzio reported the preparation of a wide range of 2 -substituted derivatives 7 by a simple nucleophilic halide displacement from 2-chloromethyl-4,5-diaryloxazoles, illustrating their usefulness (Scheme 2) [33]. In a related work, Luzzio et al. described the synthesis of 1,4-disubstituted triazoles 8 through click reaction between 2-azidomethyl-4,5diaryloxazoles and alkynes in the presence of a copper(I) catalyst (Scheme 2). The authors were able to synthesize an array of small-molecule peptidomimetics that inhibited Porphyromonas gingivalis biofilm formation [34].

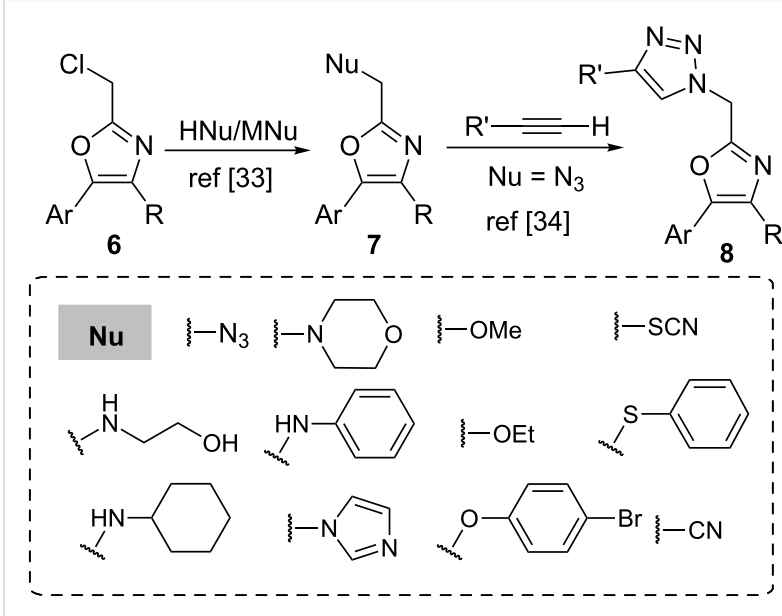

Scheme 2: Preparation of 2-functionalized oxazoles 7 from 2-(chloromethyl)oxazoles 6 and their application to the synthesis of peptidomimetics 8.

Important drawbacks observed in the generation of compounds of type 7 include the instability of the halide intermediate $\mathbf{6}$, 
which might be difficult to isolate due decomposition reactions, as well as selectivity issues during the generation of the oxazole ring. It has been shown that problems associated with unstable intermediates or reagents can be overcome with the use of continuous-flow chemistry. Continuous-flow processing has demonstrated to be an ideal tool for the development of uninterrupted multistep reactions [35-37]. The integration of several sequential steps can be readily achieved through a continuous addition of reagent streams, quenching, liquid-liquid extraction, or even filtration stages, thus avoiding the handling of unstable intermediates [35-37].

In this article we present an integrated continuous-flow procedure for the preparation of 2-(azidomethyl)oxazoles 7 starting from vinyl azides through an azirine intermediate (Scheme 3 ). The process starts with the generation of the azirine from the vinyl azide by thermolysis. Formation of azirines from vinyl azides by photolysis and thermolysis in continuous flow has been previously described [38,39]. The azirine intermediate is then reacted with a 2 -haloacyl halide at room temperature, to form the 2-(halomethyl)oxazole moiety. Subsequent reaction with an aqueous stream containing $\mathrm{NaN}_{3}$ then leads to the formation of the desired 2-(azidomethyl)oxazole. The optimization of each reaction step and the integration to a fully continuous process are described in detail.

\section{Results and Discussion Thermolysis of the vinyl azide and oxazole formation. Batch optimization}

The reaction conditions for the thermolysis of the vinyl azide and the subsequent ring expansion of the intermediate azirine to form the oxazole ring were initially optimized in batch. For these experiments, vinyl azide 1a was used as a model substrate. The small-scale batch thermolyses were carried out using sealed $1.5 \mathrm{~mL}$ vials heated in an aluminum platform. A $0.5 \mathrm{M}$ solution of substrate 1a was prepared using acetone as the sol- vent. The experiments were carried out placing $0.5 \mathrm{~mL}$ of the solution in the vial, which was sealed with a crimp-cap. The reactions were performed at three different temperatures (130-150 ${ }^{\circ} \mathrm{C}$, Table 1$)$. Notably, at $150{ }^{\circ} \mathrm{C}$ a very fast $(1 \mathrm{~min})$ and clean reaction ( $>99 \%$ purity by HPLC-UV analysis) was achieved.

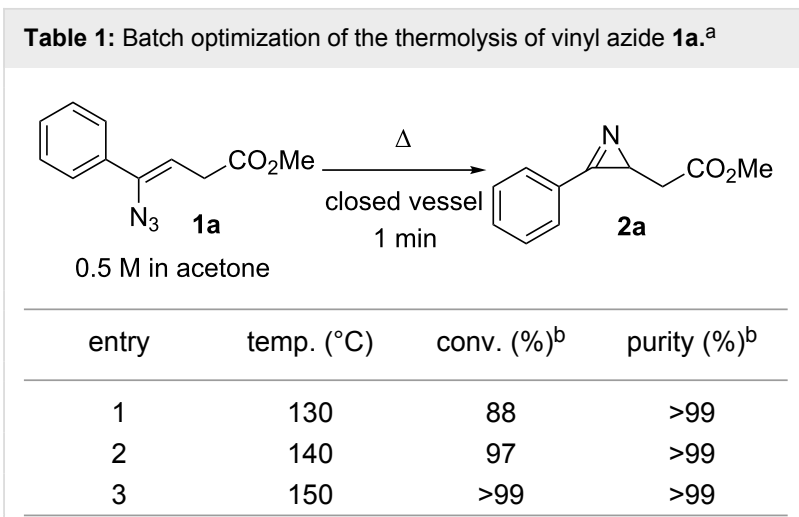

aConditions: $1 \mathrm{a}$ in acetone $(0.5 \mathrm{M}), 0.5 \mathrm{~mL}$ solution in a $1.5 \mathrm{~mL}$ vial. betermined by HPLC peak area integration at $254 \mathrm{~nm}$.

Next, the formation of 2-(bromomethyl)oxazole 6a from azirine 2a was also optimized under batch conditions. All reactions were carried out under an argon atmosphere using a $0.5 \mathrm{M}$ solution of the substrate $\mathbf{2} \mathbf{a}$ in acetone. In general, the addition of the reagents was performed at $0{ }^{\circ} \mathrm{C}$ in an ice-bath followed by stirring the reaction mixture at room temperature. When triethylamine (TEA) or $\mathrm{N}, \mathrm{N}$-diisopropylethylamine (DIPEA) were used as the base a solid formed after a few minutes in the reaction mixture (Table 2, entries 1-4), probably their corresponding ammonium bromide salts. Yet, good purities were achieved employing both bases and the incomplete conversions were ascribed to the presence of water in the reaction mixture. For this reason, further transformations were carried out in acetone dried over molecular sieves (3 Å). Using 1,5-diazabi-

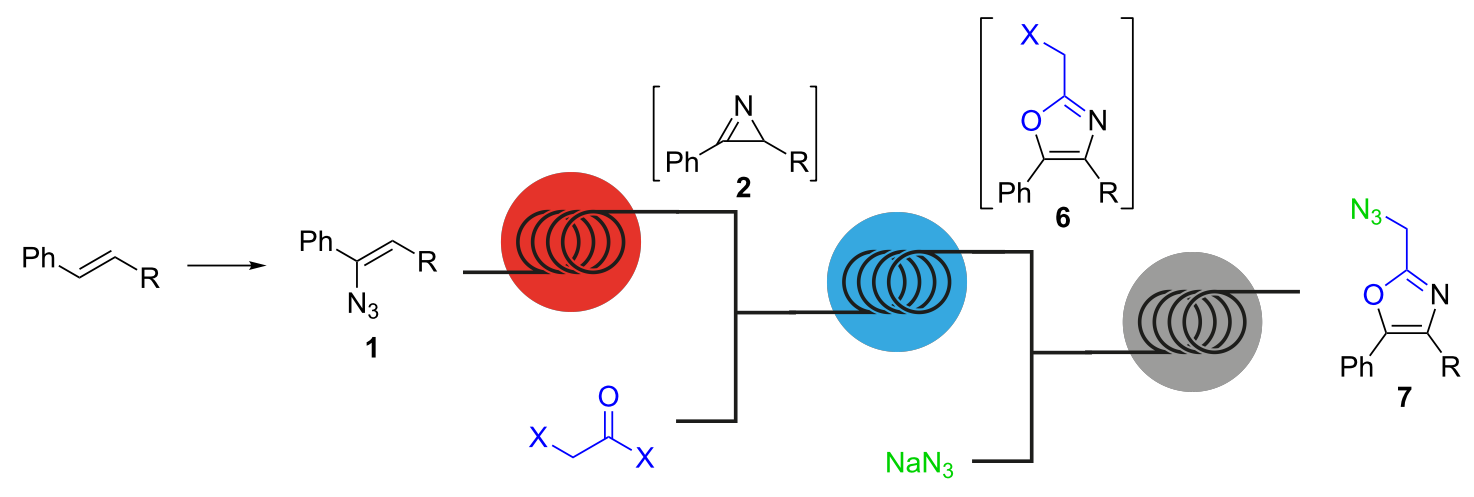


Table 2: Optimization of the reaction conditions for the generation of oxazole 6 a from azirine $2 a^{a}$

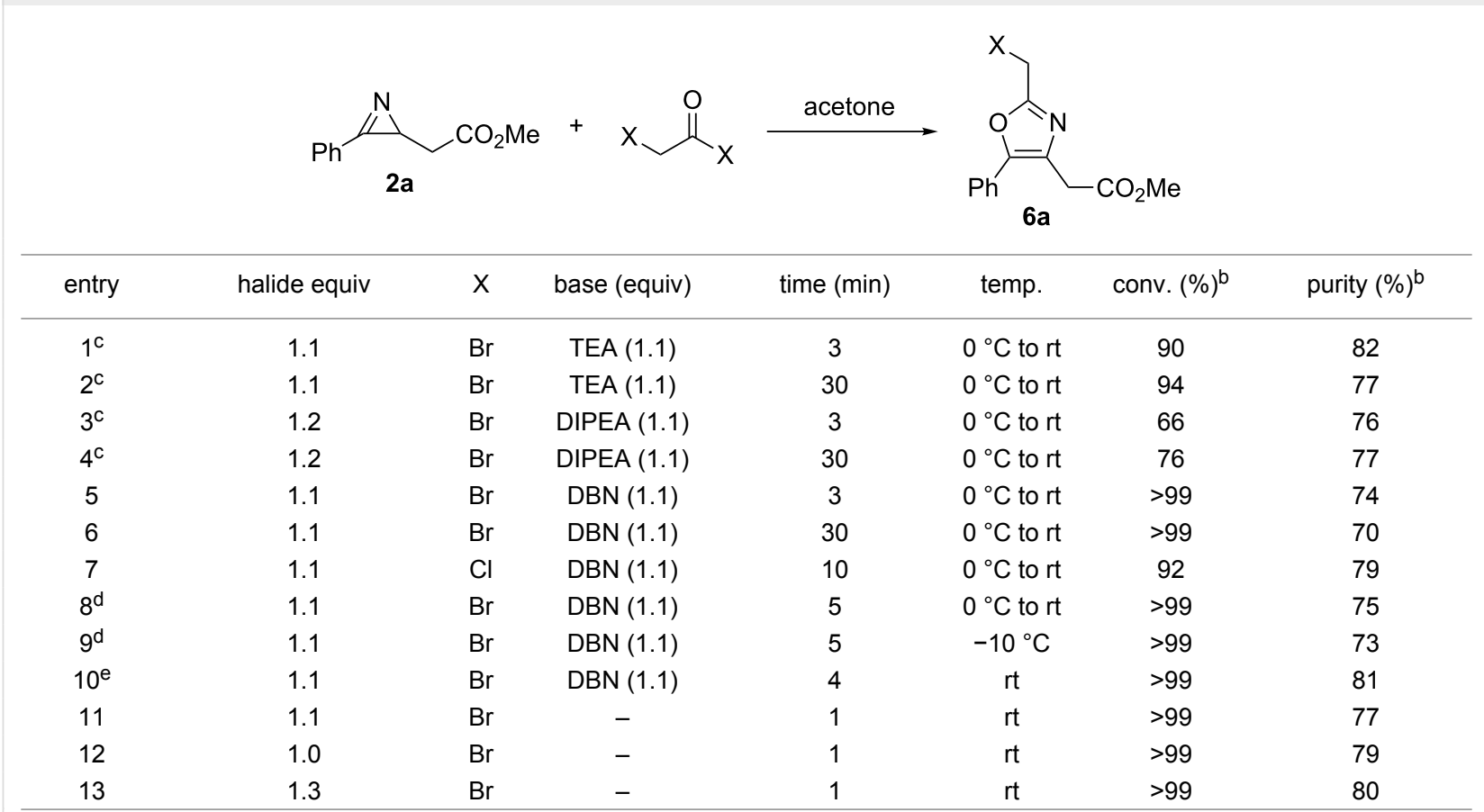

aConditions: $0.50 \mathrm{~mL}$ solution of $2 \mathrm{a}$ in acetone $(0.5 \mathrm{M})$ was mixed with $0.50-0.65 \mathrm{~mL}$ of a solution of the acyl halide in acetone $(0.5 \mathrm{M})$, followed by

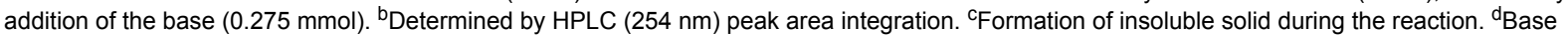

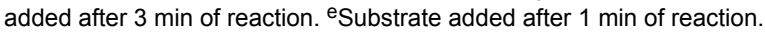

cyclo[4.3.0]non-5-ene (DBN) as the base (Table 2, entry 5) full conversion of the azirine $\mathbf{2 a}$ was observed after 3 min reaction time. In this case the oxazole 6 a was formed with $74 \%$ purity and no formation of solids was observed. At longer reaction time $(30 \mathrm{~min})$ a slight decrease in purity could be detected, probably due to slow decomposition of $\mathbf{6 a}$ (Table 2, entry 6). The reaction with chloroacetyl chloride instead of the bromo derivative delivered the corresponding (chloromethyl)oxazole with similar selectivity, the reaction was slower though, with 92\% conversion being achieved after 10 min (Table 2, entry 7). The adjustment of other parameters such as the order of added reactants or variation in temperature showed little influence on the outcome of the reaction (Table 2, entries 8-10). Notably, oxazole 6a was also formed in the absence of base (Table 2, entries 11-13). This was probably due to the weak basic character of the oxazole moiety itself, producing the oxazole hydro- bromide. Finally, the variation of the amount of bromoacetyl bromide had no significant effect on the outcome of the reaction (Table 2, entries 12 and 13).

To identify the reaction byproducts formed during the coupling of azirine $2 \mathrm{a}$ and bromoacetyl bromide, the reaction was performed on a $3 \mathrm{mmol}$ scale. The reaction mixture was quenched with $\mathrm{NaHCO}_{3}$ solution, extracted with ethyl acetate and concentrated under reduced pressure. The ${ }^{1} \mathrm{H}$ NMR analysis of the crude product mixture revealed three major side products. Purification by column chromatography permitted the separation and isolation of each component (Scheme 4), which were characterized by ${ }^{1} \mathrm{H}$ NMR, ${ }^{13} \mathrm{C}$ NMR and low-resolution mass spectroscopy. In agreement with the observations by Hassner et al. [28,29], dibromoamide 5a and its hydrolysis product 9a were obtained in addition to ketoester 10a. The distribution profile<smiles>COC(=O)CC1N=C1c1ccccc1</smiles> 
calculated by ${ }^{1} \mathrm{H}$ NMR peak integration revealed a composition of $76 \%$ product $6 \mathbf{a}$, and side products in $7 \%(5 \mathbf{a}), 10 \%(9 \mathbf{a})$ and $7 \%(\mathbf{1 0 a})$, respectively. The oxazole $\mathbf{6 a}$ was isolated as yellow solid (mp $76.3-78.1^{\circ} \mathrm{C}$ ) in $57 \%$ yield.

The optimization of the reaction conditions for the nucleophilic halide displacement with sodium azide were also evaluated in batch. A one-pot procedure starting from the azirine (without isolation of the 2-(bromomethyl)oxazole) was utilized to simulate the conditions of an integrated process. Thus, azirine $\mathbf{2 a}$ was reacted with bromoacetyl bromide in a $1.5 \mathrm{~mL}$ vial using the conditions stated in Figure 2 (1.1 equiv bromide added at $0{ }^{\circ} \mathrm{C}$, cf. Table 2 , entry 5 ) in dry acetone for $3 \mathrm{~min}$. Then, DBN was added to neutralize the acidic medium, followed by a $2.5 \mathrm{M}$ aqueous solution of $\mathrm{NaN}_{3}$ (1.1 equiv) and the resulting mixture was stirred at room temperature. A conversion of $89 \%$ to $7 \mathbf{a}$ from bromo oxazole 6 a with a selectivity of $74 \%$ was achieved after 30 min (Figure 2).

Subsequently, the amount of $\mathrm{NaN}_{3}$ was increased to 1.3 equiv to enhance the reaction rate. During the formation of the 2-(bromomethyl)oxazoles 6 addition of a base is not required (see Table 2, entries 11-13). However, neutralization of the resulting oxazole hydrobromide is required prior to the addition of $\mathrm{NaN}_{3}$ in order to avoid the generation of hydrazoic acid. Taking this into account, we decided to replace DBN by less expensive DIPEA for the subsequent reactions. Using both substrates $\mathbf{2 a}$ and $\mathbf{2 b}$, it was observed that after $5 \mathrm{~min}$ of reaction at rt, the conversion of bromo oxazoles 6 into azido oxazoles 7 was up to $92 \%$ (Table 3 , entries 1 and 4 ). When the reaction temperature was increased from rt to $50{ }^{\circ} \mathrm{C}$, good conversions were achieved after $5 \mathrm{~min}$ reaction for both for the model substrate $\mathbf{2} \mathbf{a}$ and the azirine $\mathbf{2 b}$ (Table 3, entries 2 and 5). $\mathrm{NaN}_{3}$ was not fully soluble in the reaction mixture (after mixing with the acetone medium), which would be problematic for the later translation to flow conditions. Diluting the $\mathrm{NaN}_{3}$ solution from 2.5 $\mathrm{M}$ to $1.5 \mathrm{M}$ (and therefore adding a larger volume of the solution to obtain the same excess of the reagent) resulted in fully homogeneous conditions suitable for flow processing (Table 3 , entry 3 ).

\section{Continuous-flow experiments}

Azirine formation. With the optimal conditions for the three reaction steps in hand, we translated the process to continuousflow conditions. For that purpose, individual continuous-flow reactors for each step were setup, the reaction conditions re-optimized when necessary, and finally all the steps integrated in a single continuous stream.

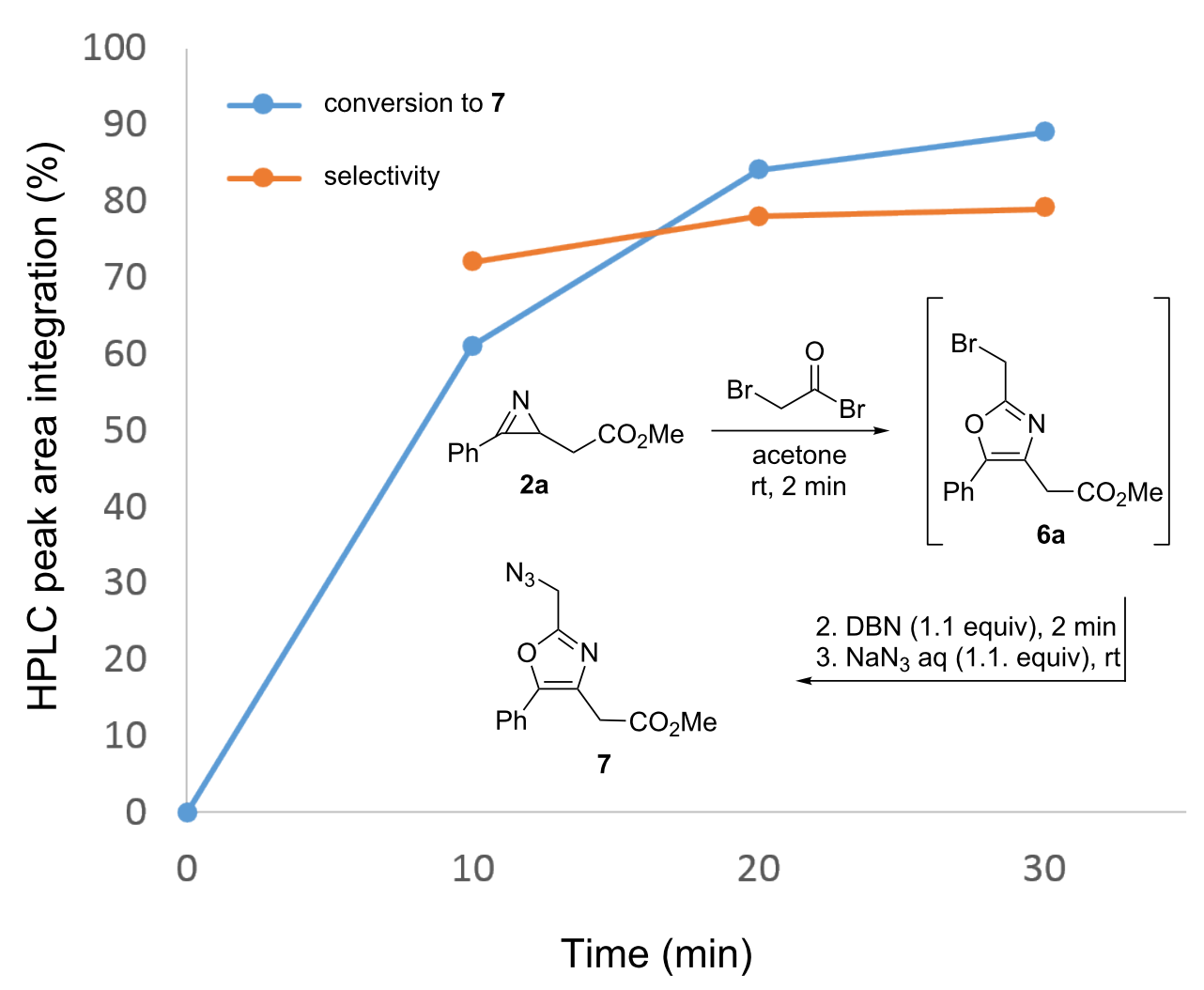

Figure 2: HPLC monitoring of the formation of 2-(azidomethyl)oxazole 7a. 
Table 3: Batch optimization of the generation of 2-(azidomethyl)oxazoles $7 \mathbf{a}$ and $7 \mathbf{b}$. $^{\text {a }}$
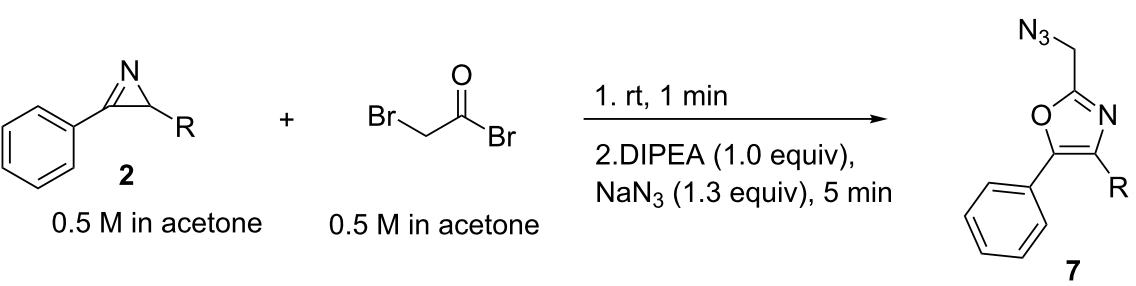

\begin{tabular}{cccccc}
\hline entry & $\mathrm{R}$ & $\mathrm{NaN}_{3}$ conc. $(\mathrm{M})$ & temp. $\left({ }^{\circ} \mathrm{C}\right)^{\mathrm{b}}$ & conv. $(\%)^{\mathrm{c}, \mathrm{d}}$ & ${\text { purity }(\%)^{\mathrm{d}}}^{\mathrm{d}}$ \\
\hline 1 & $\mathrm{CH}_{2} \mathrm{CO}_{2} \mathrm{Me} \mathrm{(2a)}$ & 2.5 & $\mathrm{rt}$ & 84 & 80 \\
2 & $\mathrm{CH}_{2} \mathrm{CO}_{2} \mathrm{Me} \mathrm{(2a)}$ & 2.5 & $50{ }^{\circ} \mathrm{C}$ & 95 & 69 \\
3 & $\mathrm{CH}_{2} \mathrm{CO}_{2} \mathrm{Me} \mathrm{(2a)}$ & 1.5 & $50{ }^{\circ} \mathrm{C}$ & 97 & 74 \\
4 & $\mathrm{H} \mathrm{(2b)}$ & 2.5 & $\mathrm{rt}$ & 92 & 69 \\
5 & $\mathrm{H} \mathrm{(2b)}$ & 2.5 & $50{ }^{\circ} \mathrm{C}$ & 97 & 67 \\
\hline
\end{tabular}

aconditions: $0.4 \mathrm{~mL}$ of a $0.5 \mathrm{M}$ solution of azirine in acetone, bromoacetyl bromide injected as a $0.5 \mathrm{M}$ solution. ${ }^{\mathrm{b}}$ Temperature for the reaction with $\mathrm{NaN}_{3}$. ${ }^{\mathrm{C}}$ Conversion for the nucleophilic displacement step. ${ }^{\mathrm{d} D e t e r m i n e d ~ b y ~ H P L C ~}(254 \mathrm{~nm})$ peak area integration.

The thermolysis of vinyl azide $\mathbf{1}$ was performed in a continuous flow reactor consisting of a perfluoroalkoxy (PFA) coil $\left(0.5 \mathrm{~mL}, 0.8 \mathrm{~mm}\right.$ i.d.) immersed in a silicon bath at $150{ }^{\circ} \mathrm{C}$. The vinyl azide solution in acetone was introduced into the reactor by a syringe pump (Syrris) with variable flow rates (Table 4) to obtain different residence times. The system was pressurized using a back-pressure regulator (BPR, Upchurch) at 17 bar (250 psi). The reaction mixture was cooled by immersing a second section of the coil reactor in an ice bath, to avoid damage of the BPR by the hot reaction mixture and evaporation of the solvent after the pressure release. Notably, flow rates had to be reduced with respect to those calculated for a residence time of $1 \mathrm{~min}$ for the generation of azirine $\mathbf{2 a}$, probably due to an expansion of the reaction mixture from the $\mathrm{N}_{2}$ generation, which reduced the actual residence time within the coil (Table 4, entries 1 and 2). Using the same flow setup azirines 2b and 2c were also successfully generated from the corresponding vinyl azides (Table 4, entries 3-5).

The continuous-flow setup was then extended by incorporating a second reagent feed with a stream containing the bromoacetyl bromide solution ( $0.5 \mathrm{M}$ in acetone, Figure 3$)$. A vessel was placed between the two reaction zones to release the $\mathrm{N}_{2}$ generated during the azirine formation, which was maintained under argon atmosphere. Using this system, the crude reaction mixture obtained from the first reaction zone, containing the azirine in acetone, was directly pumped into the second reaction zone (500 $\mu \mathrm{L} / \mathrm{min})$, mixed with the bromoacetyl bromide stream in a $\mathrm{T}$-mixer, and reacted at $30^{\circ} \mathrm{C}$ in a PFA tubing ( $1 \mathrm{~mL}$ volume). Using a flow rate of $500 \mu \mathrm{L} / \mathrm{min}$ in the feed containing the bromoacetyl bromide solution - corresponding to 1.0 equiv of the bromide with respect to the starting vinyl azide - both

Table 4: Continuous-flow generation of azirines 2 by thermolysis of vinyl azides $1{ }^{a}$<smiles>[R]C=C(N)c1ccccc1</smiles>

$0.5 \mathrm{M}$ in acetone

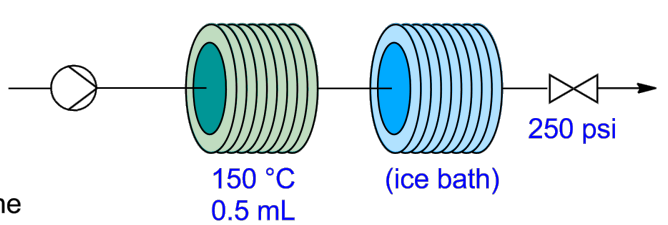

$0.5 \mathrm{~mL}$

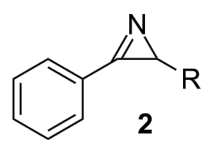

2

\begin{tabular}{|c|c|c|c|c|c|}
\hline entry & $\mathrm{R}$ & flow rate $(\mu \mathrm{L} / \mathrm{min})^{b}$ & time (min) & conv. $(\%)^{\mathrm{c}}$ & purity $(\%)^{\mathrm{c}}$ \\
\hline 1 & $\mathrm{CH}_{2} \mathrm{CO}_{2} \mathrm{Me}(2 \mathrm{a})$ & 500 & 1 & 98 & 100 \\
\hline 2 & $\mathrm{CH}_{2} \mathrm{CO}_{2} \mathrm{Me}(2 \mathrm{a})$ & 250 & 2 & 100 & 100 \\
\hline 3 & $H(2 b)$ & 250 & 2 & 91 & 92 \\
\hline 4 & $H(2 b)$ & 167 & 3 & 95 & 94 \\
\hline 5 & $\mathrm{CH}_{2} \mathrm{OH}(2 \mathrm{c})$ & 500 & 1 & 100 & 94 \\
\hline
\end{tabular}

aconditions: $0.5 \mathrm{M}$ substrate in acetone, $5 \mathrm{~mL}$ reaction mixture $(2.5 \mathrm{mmol})$ collected from the reactor output. ${ }^{\mathrm{b}}$ Theoretical residence time calculated from the flow rate and reactor volume. ${ }^{\mathrm{C}}$ Determined by HPLC $(254 \mathrm{~nm})$ peak area integration. 


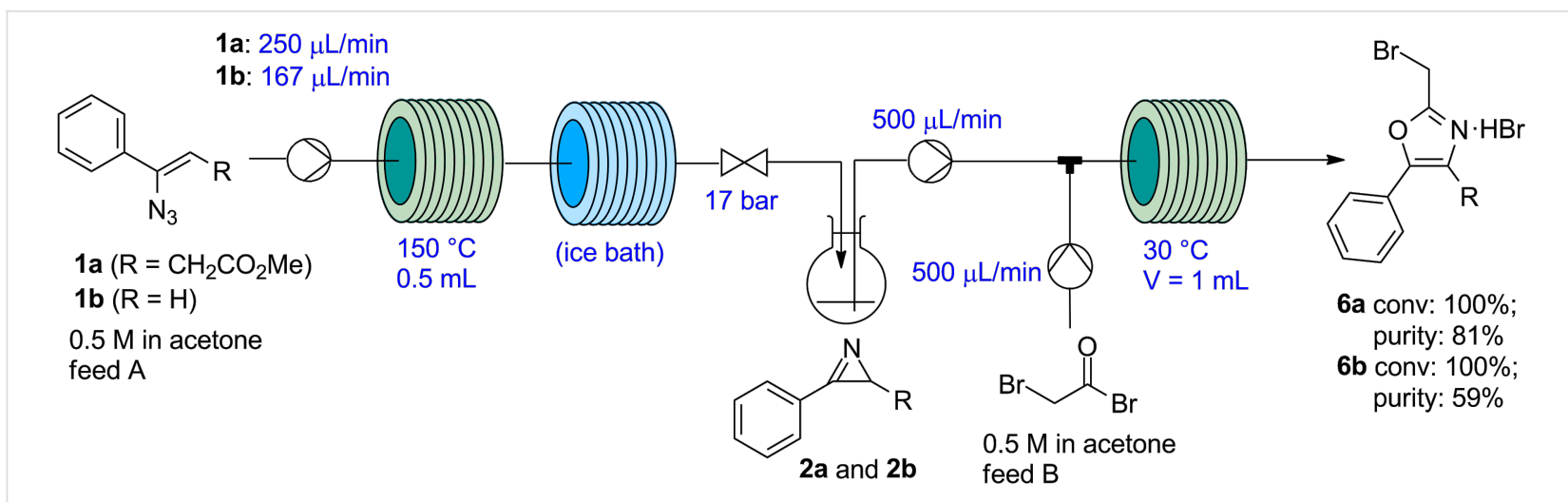

Figure 3: Continuous sequential thermolysis of vinyl azides 1 and ring expansion of azirines 2 with bromoacetyl bromide to give 2-(bromomethyl)oxazoles 6.

oxazoles $6 \mathbf{a}$ and $\mathbf{6 b}$ were obtained in full conversion, with $81 \%$ and $59 \%$ purity (HPLC). Unfortunately, the oxazoles could not be precipitated as hydrobromide salts even after cooling at $-20{ }^{\circ} \mathrm{C}$ and adding petroleum ether as co-solvent. The work-up consisted in extraction with aqueous $\mathrm{NaHCO}_{3}$, evaporation of the organic phase, and purification of the residue by column chromatography. Relatively poor isolated yields (42\% and 35\% for compounds $\mathbf{6 a}$ and $\mathbf{6 b}$, respectively) were achieved due to decomposition of the products during isolation. The decomposition of the 2-(bromomethyl)oxazoles inside the column was apparent, both when silica or neutral alumina were used as stationary phase.

Decomposition of 2-(bromomethyl)oxazoles 6 was successfully avoided by further integrating into the continuous-flow reactor the final nucleophilic halide displacement step with $\mathrm{NaN}_{3}$. The resulting 2-(azidomethyl)oxazole derivatives 7 presented higher stability and could be isolated without decomposition. Thus, two additional reagents streams were added to the flow setup
(Figure 4) containing an aqueous solution of $\mathrm{NaN}_{3}(1.5 \mathrm{M})$ and DIPEA, respectively. The three streams were mixed in a cross mixer before entering a coil reactor at $50{ }^{\circ} \mathrm{C}$ (PFA tubing, $6 \mathrm{~mL}$ ). While the vinyl azide thermolysis reactor zone was pressurized at 250 psi (17 bar), for this reactor zone 75 psi ( 5 bar) sufficed. Using this continuous-flow setup, azido oxazoles $7 \mathbf{a}$ and $\mathbf{7 b}$ were prepared from vinyl azides $\mathbf{1 a}$ and $\mathbf{1 b}$ in a threestep sequence (azirine was not isolated, the solution of the generated azirine was directly employed in the reaction described above). After reaction, 2-(azidomethyl)oxazoles 7a and 7b were purified by column chromatography, giving a threestep overall yield of $60 \%$ and $50 \%$, respectively.

The vinyl azide 1c was also subjected to the conditions described above. However, the reaction could not be completed due to solid generation in the second reactor zone (likely the hydrobromide salt of the oxazole). The reactor clogging could not be avoided either by sonication of the tubing or increasing the temperature to $50{ }^{\circ} \mathrm{C}$. Thus, the reaction was performed em-

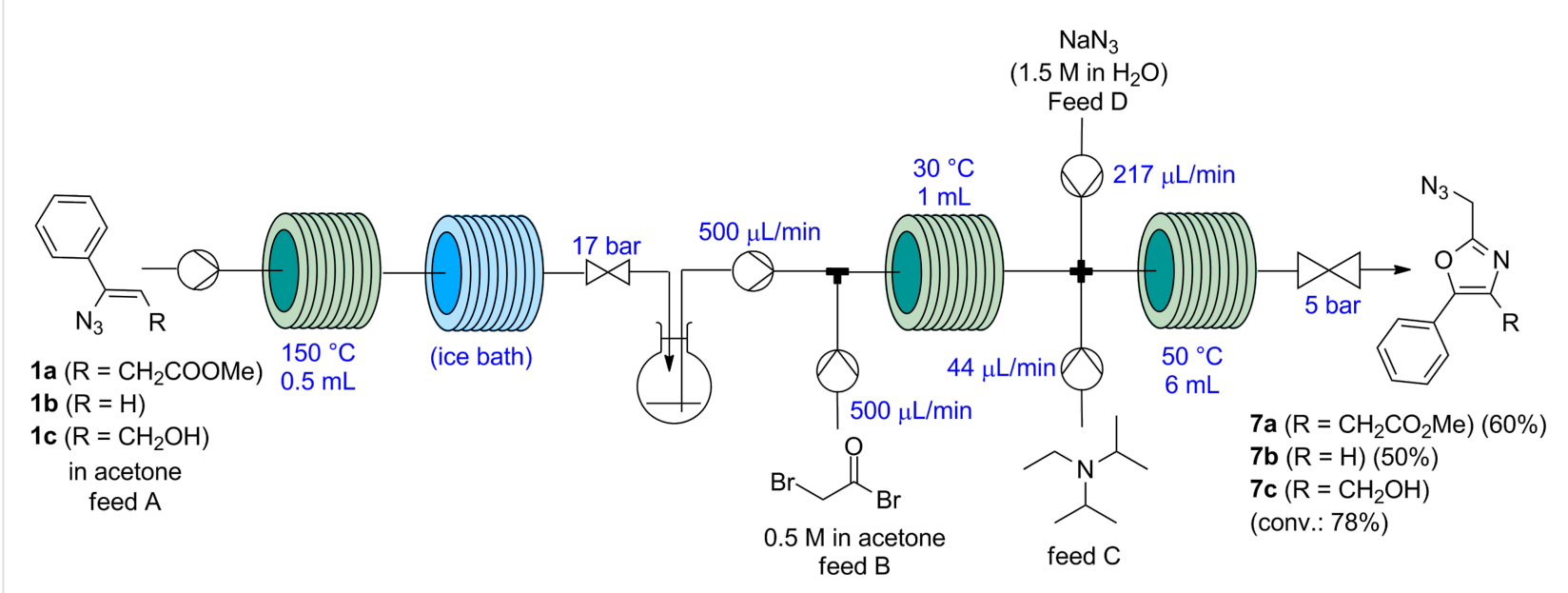

Figure 4: Continuous-flow three-step sequential synthesis of 2-(azidomethyl)oxazoles 7a-c from vinyl azides 1a-c. Yields refer to isolated yields. 
ploying a $0.25 \mathrm{M}$ solution of substrate 1c. Under diluted conditions the reaction mixture remained fully homogeneous but no full conversion from bromo oxazole $\mathbf{6 c}$ to azido oxazole $7 \mathbf{c}$ was achieved (78\%), which prevented the formation of the final product in a pure form.

\section{Conclusion}

We have developed a continuous-flow protocol for the preparation of 2-(azidomethyl)oxazoles. The procedure consists of a three-step sequential synthesis combining an initial thermolysis of the starting vinyl azide to form an azirine intermediate, followed by reaction with bromoacetyl bromide to generate the oxazole moiety, and a final nucleophilic halide displacement with $\mathrm{NaN}_{3}$ to give the desired product. After optimization of all individual steps in batch and continuous-flow mode, the complete sequence has been integrated in a single continuous-flow reactor, in which the vinyl azide is fed as substrate and the final 2-(azidomethyl)oxazole is formed and collected from the reactor output. The process avoids the isolation and handling of the unstable 2-(bromomethyl)oxazole intermediates, thus circumventing decomposition problems. The continuous reactor has been tested for three different vinyl azide substrates. Good results were obtained for compounds $\mathbf{7 a}$ and $\mathbf{7 b}$, while for $\mathbf{7 c}$ dilution was necessary to avoid clogging of the reactor.

\section{Supporting Information}

\section{Supporting Information File 1}

Experimental procedures and copies of the NMR spectra for all isolated compounds.

[https://www.beilstein-journals.org/bjoc/content/ supplementary/1860-5397-14-36-S1.pdf]

\section{Acknowledgements}

C.O.K acknowledges the Science without Borders program (CNPq, CAPES) for a "Special Visiting Researcher" fellowship. T.A.S. and N.S.S. are grateful to CAPES (Coordenação de Aperfeiçoamento de Pessoal de Nível Superior, Brazil) for fellowships. Special thanks are due to CEBIME (Laboratorio Central de Biologia Molecular e Estrutural, UFSC, Brazil) for providing the mass spectra.

\section{ORCID ${ }^{\circledR}$ iDs}

Thaís A. Rossa - https://orcid.org/0000-0001-9851-447X C. Oliver Kappe - https://orcid.org/0000-0003-2983-6007

\section{References}

1. Ibrar, A.; Khan, I.; Abbas, N.; Farooq, U.; Khan, A. RSC Adv. 2016, 6, 93016-93047. doi:10.1039/C6RA19324B
2. Hassner, A.; Fischer, B. Heterocycles 1993, 35, 1441-1465. doi:10.3987/REV-92-SR(T)6

3. Yeh, V. S. C. Tetrahedron 2004, 60, 11995-12042. doi:10.1016/j.tet.2004.10.001

4. Naik, S. R.; Harindran, J.; Varde, A. B. J. Biotechnol. 2001, 88, 1-10. doi:10.1016/S0168-1656(01)00244-9

5. Kunze, B.; Jansen, R.; Pridzun, L.; Jurkiewicz, E.; Hunsmann, G.; Höfle, G.; Reichenbach, H. J. Antibiot. 1992, 45, 1549-1552. doi:10.7164/antibiotics.45.1549

6. Greenblatt, D. J.; Matlis, R.; Scavone, J. M.; Blyden, G. T.; Harmatz, J. S.; Shader, R. I. Br. J. Clin. Pharmacol. 1985, 19, 373-378. doi:10.1111/j.1365-2125.1985.tb02656.x

7. Wang, R.; Dasgupta, A.; Ward, M. M. Ann. Rheum. Dis. 2016, 75, 1152-1160. doi:10.1136/annrheumdis-2015-207677

8. Crawford, P. F.; Crawley, K. R.; Tucker, H. A. J. New Drugs 1961, 1 279-283.

9. Chowdhury, S. R.; Chauhan, P. S.; Dedkova, L. M.; Bai, X.; Chen, S.; Talukder, P.; Hecht, S. M. Biochemistry 2016, 55, 2427-2440. doi:10.1021/acs.biochem.6b00102

10. Boger, D. L. Chem. Rev. 1986, 86, 781-793. doi:10.1021/cr00075a004

11. Turchi, I. J.; Dewar, M. J. S. Chem. Rev. 1975, 75, 389-437. doi:10.1021/cr60296a002

12. Levin, J. I.; Laakso, L. M. Oxazole Diels-Alder Reactions. Oxazoles: Synthesis, Reactions, and Spectroscopy, Part A; John Wiley \& Sons, Inc.: Hoboken, NJ, USA, 2003; pp 417-472. doi:10.1002/0471428035.ch3

13. Blond, G.; Gulea, M.; Mamane, V. Curr. Org. Chem. 2016, 20 , 2161-2210. doi:10.2174/1385272820666160216000401

14. Firestone, R. A.; Harris, E. E.; Reuter, W. Tetrahedron 1967, 23 943-955. doi:10.1016/0040-4020(67)85043-9

15. Dumond, Y. R.; Gum, A. G. Molecules 2003, 8, 873-881. doi:10.3390/81200873

16. Bresciani, S.; Tomkinson, N. C. O. Heterocycles 2014, 89, 2479-2543. doi:10.3987/REV-14-808

17. Bredereck, H.; Gompper, R. Chem. Ber. 1954, 87, 700-707. doi:10.1002/cber.19540870514

18. Gompper, R.; Christmann, O. Chem. Ber. 1959, 92, 1944-1949. doi:10.1002/cber.19590920829

19. Ritson, D. J.; Spiteri, C.; Moses, J. E. J. Org. Chem. 2011, 76, 3519-3522. doi:10.1021/jo1025332

20. Fischer, E. Ber. Dtsch. Chem. Ges. 1896, 29, 205-214. doi:10.1002/cber.18960290143

21. Ingham, B. H. J. Chem. Soc. 1927, 692-700. doi:10.1039/JR9270000692

22. Kotani, E.; Kobayashi, S.; Adachi, M.; Tsujioka, T.; Nakamura, K.; Tobinaga, S. Chem. Pharm. Bull. 1989, 37, 606-609. doi:10.1248/cpb.37.606

23. Ishiwata, Y.; Togo, H. Tetrahedron 2009, 65, 10720-10724. doi:10.1016/j.tet.2009.09.109

24. Ning, Y.; Otani, Y.; Ohwada, T. J. Org. Chem. 2017, 82, 6313-6326. doi:10.1021/acs.joc.7b00904

25. Brahma, S.; Ray, J. K. J. Heterocycl. Chem. 2008, 45, 311-317. doi:10.1002/jhet.5570450203

26. Sauers, R. R.; Hagedorn, A. A., III; Van Arnum, S. D.; Gomez, R. P.; Moquin, R. V. J. Org. Chem. 1987, 52, 5501-5505. doi:10.1021/jo00234a001

27. Zeng, T.-T.; Xuan, J.; Ding, W.; Wang, K.; Lu, L.-Q.; Xiao, W.-J. Org. Lett. 2015, 17, 4070-4073. doi:10.1021/acs.orglett.5b01994

28. Fowler, F. W.; Hassner, A. J. Am. Chem. Soc. 1968, 90, 2875-2881. doi:10.1021/ja01013a026 
29. Hassner, A.; Burke, S. S.; I, J. C. J. Am. Chem. Soc. 1975, 97, 4692-4700. doi:10.1021/ja00849a035

30. Smith, A. B., III; Minbiole, K. P.; Freeze, S. Synlett 2001, 1739-1742. doi:10.1055/s-2001-18096

31. Linder, J.; Blake, A. J.; Moody, C. J. Org. Biomol. Chem. 2008, 6, 3908-3916. doi:10.1039/b810855b

32. Kuntiyong, P.; Lee, T. H.; Kranemann, C. L.; White, J. D. Org. Biomol. Chem. 2012, 10, 7884-7899. doi:10.1039/c2ob25766a

33. Patil, P. C.; Luzzio, F. A. Tetrahedron Lett. 2016, 57, 757-759. doi:10.1016/j.tetlet.2016.01.016

34. Patil, P. C.; Tan, J.; Demuth, D. R.; Luzzio, F. A. Bioorg. Med. Chem 2016, 24, 5410-5417. doi:10.1016/j.bmc.2016.08.059

35. Wegner, J.; Ceylan, S.; Kirschning, A. Adv. Synth. Catal. 2012, 354, 17-57. doi:10.1002/adsc.201100584

36. McQuade, D. T.; Seeberger, P. H. J. Org. Chem. 2013, 78, 6384-6389. doi:10.1021/jo400583m

37. Ahmed-Omer, B.; Barrow, D. A.; Wirth, T. ARKIVOC 2011, iv, 26-36. doi:10.3998/ark.5550190.0012.404

38. Cludius-Brandt, C.; Kupracz, L.; Kirschning, A. Beilstein J. Org. Chem. 2013, 9, 1745-1750. doi:10.3762/bjoc.9.201

39. Cantillo, D.; Gutmann, B.; Kappe, C. O. Org. Biomol. Chem. 2016, 14, 853-857. doi:10.1039/C5OB02425K

\section{License and Terms}

This is an Open Access article under the terms of the Creative Commons Attribution License (http://creativecommons.org/licenses/by/4.0), which permits unrestricted use, distribution, and reproduction in any medium, provided the original work is properly cited.

The license is subject to the Beilstein Journal of Organic Chemistry terms and conditions:

(https://www.beilstein-journals.org/bjoc)

The definitive version of this article is the electronic one which can be found at: doi:10.3762/bjoc. 14.36 